\title{
O IBESP EM SEU MOMENTO: uma análise genética e cronológica dos Cadernos do Nosso Tempo
}

\author{
Fernanda Xavier da Silva*
}

\begin{abstract}
O presente trabalho apresenta uma análise da revista Cadernos do Nosso Tempo. Publicada entre os anos de 1953 e 1956 pelo Instituto Brasileiro de Economia, Sociologia e Política (IBESP), ela assinalou um esforço da inteligência nacional em impulsionar um pensamento genuinamente brasileiro. Combinando artigos de interpretação econômica, sociológica, política e cultural do Brasil com a análise dos fenômenos do seu tempo, acabou por consolidar um amplo diagnóstico do país, uma análise contundente das condições e formas de se alcançar o desenvolvimento, temática principal, móvel, que uniu os intelectuais do IBESP, permeando todos os números dos Cadernos sem, contudo, permanecer imutável. A nosso ver, uma vez que as ideias buscam responder aos desafios e dilemas postos pelo contexto específico, o modo como o desenvolvimento foi pensado e trabalhado mudou pari passu com as transformações experimentadas pelo país, o que torna importante, tanto genética como cronologicamente, o estudo dos Cadernos.
\end{abstract}

Palavras-chave: Pensamento social brasileiro. Desenvolvimentismo. IBESP. Cadernos do Nosso tempo.

\section{INTRODUÇÃO}

Criado em 1953, o Instituto brasileiro de Economia, Sociologia e Política (IBESP) cristalizou a "vocação de estudos dos problemas brasileiros", iniciada em 1952, nas reuniões do Grupo Itatiaia, ${ }^{1}$ dando-lhe uma forma institucional (Bariani, 2005, p. 250). Conquanto vivesse de pequenas contribuições de seus próprios membro ${ }^{2}$ e com encontros extemporâneos, tal grupo editou uma revista, os chamados Cadernos do Nosso Tempo, onde foram publicados os textos dessas discussões. Editados entre 1953 e 1956, totalizam apenas cinco volumes, mas que vieram a marcar época.

Como bem assinala Bariani, os trabalhos aí publicados "geralmente não contêm

* Universidade Federal de Itajubá, Instituto de Engenharia de Produção e Gestão - UNIFEI.

Pinheirinho. Cep: 37500903. Itajubá - Minas Gerais - Brasil.fernanda.xav@hotmail.com

${ }^{1}$ Conjunto de intelectuais que se reuniam, no último fim de semana de cada mês, no Parque Nacional do Itatiaia situado a meio caminho do Rio de Janeiro e de São Paulo - para discutir teoria, desejosos de "impulsionar um pensamento genuinamente brasileiro" (Bariani, 2005, p. 250).

${ }^{2}$ Na verdade, se mantinha com as contribuições de Hélio Jaguaribe, pois era ele quem "financiava do próprio bolso, com seus proventos de advogado, a edição da revista Cadernos do Nosso Tempo." (Pereira, 2005, p. 131). citações e/ou preocupações acadêmicas”, pois eram, antes, textos engajados, "textos de construção e combate que denotam a preocupação essencial dos autores: influir decisivamente na realidade brasileira" (Bariani, 2005, p. 250). Ainda assim, traziam importantes contribuições teóricas a questões latentes na década de 1950, tais como o ademarismo, o populismo, e, sobretudo, o desenvolvimento. Conforme Schwartzman, "[...] a importância do IBESP e dos Cadernos é que eles contêm, no nascedouro, toda a ideologia do nacionalismo, que ganharia força cada vez maior no país nos anos subsequentes." (Schwartzman, 1979, p. 03). Chama também a atenção a organicidade de seus textos e volumes, o que torna possível "uma análise sistemática do projeto em formulação” (Bariani, 2005, p. 251).

Devido às limitações orçamentárias do grupo, combinadas à hábil negociação empreendida por Hélio Jaguaribe e Roland Corbisier junto ao governo, o IBESP transformou-se, em julho de 1955, no Instituto Superior de Estudos Brasileiros, o ISEB. Como órgão permanente do Ministério da Educação e Cultura, tinha a função formal de promover cursos 
avulsos, conferências e publicações, ao passo que se pretendia: um laboratório de pesquisa da realidade brasileira. ${ }^{3}$ Os Cadernos deixaram então de ser publicados, porém sem significar o abandono dos ideais ali traçados.

Como bem observa Bariani (2005, p. 255), se comparado ao IBESP, o ISEB “alargou o espectro das análises, agregou novos temas e aventurou-se tanto no debate intelectual quanto social”, mantendo, no entanto, a influência da análise econômica da Comissão Econômica para a América Latina (Cepal) e da aplicação do existencialismo à realidade social, além da posição de engajamento ali sempre presente (Bariani, 2005). O ISEB consolidou, pois, "uma tentativa de levar à frente os ideais e o projeto do IBESP" embora radicalizando-os: passa de simples instituição de saber a ator político (Schwartzman, 1979, p. 06). Isso talvez explique por que, não obstante essa origem comum, muitos são os trabalhos que analisam o ISEB e seus membros, enquanto são poucos os que se dedicam ao IBESP e aos Cadernos. ${ }^{4}$

De modo a contribuir para o preenchimento de tal lacuna, o presente artigo procura analisar os cinco números da revista sob uma perspectiva genética ${ }^{5}$ e cronológica, isto é, examina não apenas os principais temas, problemas e ideias apresentados nos Cadernos, mas

${ }^{3}$ Conforme Hélio Jaguaribe, o projeto inicial "previa duas coisas: em primeiro lugar algo como o Collège de France $\therefore$ [órgão que reconhece pessoas sem carreira na universida-

$\$$ de, porém importantes luminares]. Em segundo lugar [...]

uma grande editora que permitisse ao intelectual brasi-

$\sum^{\pi}$ leiro um apropriado instrumento de difusão de ideias e

o acesso a livros de alta cultura, traduzidos para o portu-

‡̛ guês”. Porém, por questões financeiras, tal plano só pôde

o se concretizar em escala mais modesta: "um instituto de

\% estudos que desenvolvesse um esforço editorial” (Jaguari-

be, 2005, p. 34-35).

న ${ }^{4}$ Fora o trabalho clássico de Schwartzman, encontramos

. apenas outros dois trabalhos que versam especificamente

A sobre os Cadernos: o de Edson Bariani, acima citado, e o

of de Cristina Buarque de Hollanda, publicado em 2012, na N revista Dados.

$\rightarrow$

iิ ${ }^{5}$ Abordagem comum aos estudos de teoria literária, que consiste em pensar o livro em seu caráter processual, isto

$\stackrel{2}{2}$ é, analisar o movimento de criação de um livro desde क - cepção da crítica, até chegar ao livro efetivamente publi$\mathbb{I}$ cado. Nova em estudos do pensamento social brasileiro,

fol abordagem implica estudar um determinado livro, a

o obra de um autor e suas ideias como um processo, um

movimento, "objeto de disputas cognitivas e políticas" em

um dado ambiente histórico-sociológico, e não como reali-

J dade ontológica estável (Bittencourt, 2011, p. 11). também como eles são elaboradas e modificadas pari passu com as transformações experimentadas por seu contexto específico.

\section{OS CADERNOS DO NOSSO TEMPO}

Congregando, entre seus autores-editores, pessoas com trajetórias profissionais, intelectuais e políticas diversas - entre eles, Alberto Guerreiro Ramos, Cândido Mendes de Almeida, Ewaldo Correia Lima, Heitor Lima Rocha, Hélio Jaguaribe, Hermes Lima, Ignácio Rangel e Roland Corbisier -, sem uma "maneira unívoca e coerente de ver as coisas" (Schwartzman, 1979, p. 3), os artigos publicados nos Cadernos eram, ainda assim, " bastante afinados entre si, tanto na definição, quanto no tratamento dos temas." (Hollanda, 2012, p. 610). Talvez reflexo da ascendência intelectual de Hélio Jaguaribe ${ }^{6}$ (Pereira, 2002), talvez pela "adesão a um sentido comum da política”, o fato é que seus colaboradores pareciam unir-se em torno da discussão, do exame da crise e do futuro do Brasil: "autores e indivíduos diluíam-se em projeto coletivo dedicado à análise e à reforma das condições de vida no país." (Hollanda, 2012, p. 610).

Tanto é que, em todos os números dos Cadernos, seus colaboradores "compunham um grupo razoavelmente estável e enxuto" e, em muitos de seus artigos, a autoria não se encontrava declarada, ou seja, o autor simplesmente não era identificado, posto que se tratava de uma produção coletiva (Hollanda, 2012, p. 610). Não obstante isso, tendo em vista os fatos e rumos que marcaram a história do ISEB, ${ }^{7}$

${ }^{6}$ Principal articulador das reuniões do Itatiaia, financiador dos Cadernos e, posteriormente, estrela central do ISEB, foi ele o responsável por ditar tanto o perfil do (s) grupo (s) - acentuadamente acadêmico, até a crise de 1958 (vide nota 6) - como sua agenda temática, não obstante defender a pluralidade e a liberdade de pensamento.

${ }^{7}$ Refiro-me à crise gestada quando da publicação do livro O nacionalismo na atualidade brasileira por Hélio Jaguaribe, em 1958. Por apresentar teses polêmicas - opunha nacionalismo de meios ao nacionalismo de fins e legitimava a utilização de capital estrangeiro para a promoção do desenvolvimento nacional -, sua publicação acabou por tornar patente a divisão interna do instituto entre partidários de um "ISEB mais acadêmico e pluralista" versus os 
uma análise mais detida do conteúdo da revista revela já existirem ali algumas das divergências (de modos de pensar e mesmo de projetos) que levaram à cisão do instituto nos anos seguintes.

Já no que concerne à forma, embora a composição dos Cadernos não fosse muito rígida - em cada um dos exemplares as subdivisões variavam tanto no nome como no conteúdo - três eram as seções principais: panorama nacional, panorama internacional e ensaios. Enquanto na primeira seção eram publicados textos e análises sobre a situação política e econômica nacional (com o predomínio ora de uma esfera, ora de outra, resultado do contexto específico a que seus autores-editores procuravam dar resposta ${ }^{8}$ ), na segunda, encontravamse artigos a respeito da situação específica de alguns países e (ou) da política internacional como um todo. De igual modo, ambas as seções lidavam com questões de última hora desafios e rumos da política no Brasil, quadro da Guerra Fria, etc. -, ao passo que a terceira seção voltava-se para a publicação de textos e ensaios produzidos pelos membros do próprio IBESP. Com temática vasta e diversa, conteúdo mais profundo e (ou) teórico, às vezes pouco ligado às questões do momento - caso de alguns artigos de Guerreiro Ramos, de conteúdo mais sociológico e pouco conjuntural -, integravam, porém o projeto maior da revista de não apenas refletir sobre os problemas do Brasil em todas as suas dimensões, mas também apontar caminhos para sua resolução. Logo, enquanto, nas outras duas seções, era feito um diagnóstico da realidade, nos ensaios se concebiam ou assinalavam caminhos para seu enfrentamento (caso dos ensaios de abertura e fechamento dos Cadernos: "A crise brasileira" e "Por uma política nacional de desenvolvimento”).

favoráveis a um "ISEB mais ativista" e, em consequência, nacionalista (Pereira, 2002, p. 153). Ao mesmo tempo veio à tona o projeto de Guerreiro Ramos de assumir não apenas a direção do instituto, mas também a direção intelectual do grupo (Sodré, 1978). Ouso dizer que foi a última a principal responsável pela crise e posterior saída de diversos membros do ISEB, dentre eles o próprio Guerreiro Ramos, além de Hélio Jaguaribe.

${ }^{8}$ É esse, por exemplo, o caso do número três, escrito logo após o suicídio de Getúlio Vargas.
Vale também destacar que, não obstante as diferenças (de fato, bastante eventuais) entre seus colaboradores, os Cadernos possuíam uma orientação teórica própria, marcadamente historicista, marxista, e, sobretudo, mannheimiana. Como bem observa Hollanda, por um lado, a reflexão "sobre o estado da arte da sociedade e da política brasileira" passava pela compreensão "do que foi, do que é”, para, daí, pensar "o que deve ser e como deve passar a ser". Tal reflexão era feita sempre tendo em vista a infraestrutura econômica específica do país. Por outro lado, subsistia, entre seus autores-editores, "um forte sentido de responsabilidade social”, como se eles atribuíssem " a si e a extratos progressistas da sociedade um papel fundamental na condução da política nacional por bons rumos." (Hollanda, 2012, p. 611). O IBESP, em seus Cadernos, procurou não apenas congregar intelectuais com vistas a um "estudo sistemático do Brasil" e de seu subdesenvolvimento, mas também constituirse como uma intelligentsia que, atuando à maneira mannheimiana - como camada ilustrada, situada não acima, mas entre as classes sociais, analisando as questões em pauta sob várias perspectivas em favor da síntese (Mannheim, 1974) -, acabou por se notabilizar "como pretensa consciência social dos dilemas do país" (Bariani, 2005, p. 255). Até porque, como bem pontua Schwartzman, "para o IBESP, eram os intelectuais, mais do que suas ideias ou partidos, que poderiam, um dia, tomar o destino do país em suas mãos." (Schwartzman, 1979, p. 4)

Daí que "análise e normatividade implicavam-se reciprocamente" nos artigos e ensaios da revista. Pois, como se registra na Apresentação de seu primeiro número, a preocupação básica dos Cadernos era compreender concretamente a realidade, "as possibilidades e necessidades do homem brasileiro nas [suas] condições de lugar e tempo", para, assim, "fundamentar uma ação autêntica" (CNT, 1953a, p. 2). Isso explica a inscrição contida na contracapa dos cinco números da revista: "Os problemas do nosso tempo na perspectiva do 
Brasil; os problemas do Brasil na perspectiva do nosso tempo".

\section{OS PROBLEMAS DO NOSSO TEMPO E DO BRASIL}

Nessa mesma Apresentação (texto de autoria desconhecida), os anos 1950 foram caracterizados como uma época problemática, uma época de crise, como resultado dos seguintes fatores:

[...] perda de validade ou vigência das crenças que pautavam a conduta das épocas precedentes, confusão causada pela inexistência de critérios de seleção e julgamento, instabilidade da vida, sujeita a crises econômicas e sociais que se superpõem, alienação causada pela massificação e proletarização e precariedade das coisas, sob o risco iminente da aniquilação atômica [...] (CNT, 1953a, p. 2).

Nela, o autor (ou os autores) entendia que o próprio viver tornou-se um problema. É, porém, em A crise do nosso tempo e do Brasil, texto de autoria de Hélio Jaguaribe, que tal questão foi mais bem matizada.

Segundo Hélio Jaguaribe, o problema do seu tempo era resultado da conjunção de duas crises. De um lado havia a crise das crenças, pois o cristianismo, apesar de se manter como - essência da religião e da cultura ocidentais, กิ "não consegue mais ordenar coerente e sistematicamente nossas crenças e nossos valores", haja vista a ascensão do racionalismo e desajustamento e o descompasso entre nossas instituições e nossa realidade e entre nossas posições ideológicas e nossas verdadeiras instituições" (Jaguaribe, 1954, p. 11).

Conforme o autor, a alienação colonialista brasileira, expressão do retardamento cultural e econômico do país, fazia com que considerássemos os problemas nacionais "segundo a perspectiva dos interesses alienígenas", quando devíamos fazê-lo "a partir da realidade brasileira, da posição do Brasil na América Latina e desta no mundo" (Jaguaribe, 1954, p. 2). Entender e caracterizar qual era essa realidade foi, pois, a questão central do texto A crise brasileira, ensaio de estreia da revista.

Esse texto, também de autoria de Hélio Jaguaribe, buscava elucidar quais eram os problemas, as características e as causas da crise no Brasil. Conforme o autor, a crise brasileira apresentava dois planos de profundidade, o estrutural e o conjuntural, e quatro aspectos básicos: econômico, social, cultural e político. A primeira, a crise econômica, era resultante do fato de o Brasil ter ultrapassado o nível de tolerância do processo de subdesenvolvimento. A manutenção de uma economia pautada na monocultura de exportação, somada à dependência crescente de certas matérias-primas e de maquinaria, tornou o saldo do balanço de pagamentos cada vez mais insuficiente ante as atuais exigências de importação, resultantes da baixa elasticidade dos nossos termos de troca, em oposição à alta elasticidade dos bens importados. Acrescentese a isso o alto custo da produção nacional fruto da dependência da importação, da baixa racionalização da produção, e (ou) da insuficiência da infraestrutura nacional - e, como consequência, a baixa acumulação de capital e de formação de tecnologia. Nesse quadro, a economia brasileira era incapaz de atender à demanda interna ${ }^{9}$ (Jaguaribe, 1953b).

9 Jaguaribe e o IBESP bebem aí das teses consagradas no Manifesto de Prebisch de 1949. Recusando as teses da teoria ortodoxa, Prebisch apontava para a disparidade de condições a partir das quais os países centrais e periféricos se inseriam no mercado internacional: "enquanto os primeiros reteriam os frutos do aumento da produtividade, os outros sofreriam os efeitos da alta dos produtos que importam e baixa dos produtos de exportação". Segundo o 
Para Hélio Jaguaribe, tal configuração acabava por resultar no surgimento de novos fenômenos de subdesenvolvimento, expressos na desproporção crescente entre a renda dos assalariados e a dos proprietários e entre as diferentes regiões do país. Intensificada por um contexto de inflação, haja vista a imoderada expansão do crédito, eis que se formava, nacionalmente, uma conjuntura de escassez e carestia, quer por efeito deliberado - resultado do monopólio ou oligopólio de alguns setores, como o de transporte -, quer involuntariamente - resultado da insuficiência de bens e serviços, de transporte e armazenamento ou da concentração tanto da demanda, como da concorrência (Jaguaribe, 1953b, p. 121).

Já a crise social consistia na transformação da tensão entre as classes num antagonismo irredutível, resultante do baixo índice de renovação das elites dirigentes, acompanhado da pressão ascendente das camadas populares e da decadência do capitalismo. Conforme o autor, as transformações pelas quais o país passou, ao longo de sua história, significaram o solapamento das bases em que se assentavam o domínio da burguesia latifundiária e da classe média, forçando a participação das massas no processo econômico e político. Todavia, até então, a partir de uma prática demagógico -assistencialista, responsável por uma sorte de promessas ao proletariado, tais classes vinham assegurando a manutenção da política de clientela ${ }^{10}$ (Jaguaribe, 1958) e do regime agroe-

autor, a escassez de dólares gerada pelo déficit do balanço de pagamentos e o baixo nível dos salários no mercado interno representavam dois dos principais impeditivos ao desenvolvimento desses países, não superados pela lógica ortodoxa da divisão internacional do trabalho. Demandava, portanto, "intervenção estatal” (Martins, 2008, p. 80).

${ }^{10}$ Embora citado aqui, é somente em seu livro Condições institucionais ao desenvolvimento (1958), publicado pelo ISEB, que Hélio Jaguaribe deixou claro o que entendia por política de clientela. Conforme o autor, tratava-se da política surgida com a urbanização brasileira, responsável por gerar uma nova classe: a classe média. Uma vez que o processo produtivo brasileiro apresentava uma relação de classes bastante simples - resumia-se em classe dominante dos fazendeiros e (ou) burguesia mercantil e classe dominada do campesinato, - essa classe encontrava-se deslocada do processo produtivo. Isso fez com que se organizassem clientelas em torno das fazendas, posteriormente consolidadas e homologadas pelo regime federativo, via prática do voto de favor, barganhado pelo emprego de favor. xportador. Como resultado, ampliou-se o antagonismo entre as massas e as elites, cuja principal consequência foi tanto impedir a formação de um projeto de convivência das classes, como acentuar "os egoísmos de classe, o imediatismo oportunista dos indivíduos e as tendências dissociativas" (Jaguaribe, 1953b, p. 129).

No que tange ao aspecto cultural, a crise tratava do agravamento, em termos críticos, da incultura nacional. Isso ocorria, primeiramente, devido à prática da economia de exploração. Conforme o autor, o processo de economia de exploração, aqui implantado, atenuou as provocações do meio rural, responsáveis pela formação da cultura. Por auferir seus proventos da simples plantação e (ou) do comércio, a burguesia latifundiária e urbana não precisou "aprimorar técnicas complexas para assegurar sua subsistência” (Jaguaribe, 1953b, p. 130). Ao mesmo tempo, ao parasitarem em torno do Estado, a classe média não foi levada a desenvolver modernos mecanismos administrativos. Somando a isso as características da colonização portuguesa - que não apenas impediu o florescimento de uma cultura nacional, como também, por não ter sido atingida pela Reforma, não forjou novos instrumentos mentais para compreender o mundo moderno -, o Brasil mostrava-se culturalmente despreparado para enfrentar a crise do seu tempo, isto é, nosso pensamento não dispunha de categorias "para equacionar a problemática filosófica e sociológica do mundo contemporâneo", e carecia de conhecimento técnico e administrativo para enfrentar as tarefas da vida econômica e social ${ }^{11}$ (Jaguaribe, 1953b, p. 130).

${ }^{11}$ Em O problema do negro na sociologia brasileira, publicado no segundo número dos Cadernos, Guerreiro Ramos chamou a atenção para outro aspecto dessa crise: a alienação cultural da ciência, mais precisamente da sociologia brasileira. Analisando os estudos sobre o negro no Brasil o autor criticava o fato de o negro ser estudado aqui "a partir de categorias e valores induzidos pela realidade predominantemente europeia, [...] por conceitos pobres de experiências cognitivas genuinamente vividas”. Embora atribuísse certa universalidade aos "princípios gerais do conhecimento", entendia que o trabalho científico estava sempre articulado a uma realidade, a um meio especifico. Nesse sentido, fazia-se necessária "a elaboração de uma consciência sociológica verdadeiramente nacional, não só a respeito da situação do homem de cor brasileiro", mas do Brasil como um todo (Guerreiro Ramos, 1954, p. 189- 
Por fim, segundo ele, a crise política "exprime as dificuldades e desorientação" indicada nos itens precedentes e assinalava o colapso do sistema cartorial, ${ }^{12}$ praticado desde o Império. Conforme o autor, a expansão dos fatores de produção, quando das duas guerras mundiais, significou um aumento na demanda por serviços públicos efetivos, incompatível com a estrutura do estado cartorial. Ao mesmo tempo, no plano das relações internacionais, os Estados passaram crescentemente a intervir em favor de seus interesses econômicos. Todavia, faltava ao Estado brasileiro uma estrutura necessária para tal, o que o tornava "presa dos Estados que programam e executam coerentemente uma tal política” (Jaguaribe, 1953b, p. 143). Para Hélio Jaguaribe, esse fato tornavase ainda mais grave porque se tratava de um contexto de formação de uma hegemonia mundial, cuja principal tendência era a de "o Estado vencedor exercer uma política de economia de exploração em relação aos demais países, tanto mais acentuadamente quanto menor fosse a capacidade de resistência de cada país" (Jaguaribe, 1953b, p. 144).

Diante disso, que rumo tomar? A procura contínua por uma resposta a essa pergunta e as transformações por ela experimentadas deixam entrever o contexto de constante tensão

ง 190). Em Condições institucionais ao desenvolvimento, $\therefore$ Jaguaribe incorpora tal abordagem e passa a caracterizar ¿ a crise cultural como "importação mecânica, transplan○ tação automática e acrítica de categorias e princípios, de ¿ critérios e valores elaborados pelos países culturalmente $\Sigma$ desenvolvidos”, mas inadequados ao período faseológico $\stackrel{\infty}{+}$ do país (Jaguaribe, 1958).

ก่ 12 Aqui também falta uma explicação do que seria o estado ๓ి cartorial. Em Condições institucionais ao desenvolvimen$\dot{2}$ to, Hélio Jaguaribe caracterizou o estado cartorial como " "produto da política de clientela e, ao mesmo tempo, o ins$\curvearrowright$ trumento que a exerce e a conserva", por meio do ofereci-

¿ mento de cargos no serviço público. Para ele, ao subsidiar

- as clientelas e envolver a classe média marginal, o Estado

จ converteu-se em uma "pirâmide infinita de cargos", cuja

$>$ única função era se autossustentar através da arrecadação

ث. (Jaguaribe, 1958, p. 22). No entanto, ainda no quarto nú-

- mero (1955) dos Cadernos, Oscar Lorenzo Fernandes, em

$\stackrel{\pi}{\geq}$ sua Análise da existência da realidade brasileira, citando

๙ os estudos de Jaguaribe, definiu o processo cartorial como

. um sistema de distribuição de privilégios - "por meras cir-

TI cunstâncias ou condições de classe" - incompatíveis com

J “as finalidades e condições de eficiência” dessas estrutu-

ras e (ou) instituições, até porque "o indivíduo que logra o

privilégio [...] nada tem a ver com o para que e o como [...]

das estruturas ou instituições em que se encontra inseri-

ษ do" (Fernandes, 1955, p. 159, grifo nosso). e mudança em que os Cadernos foram publicados, além de expressar uma perspectiva do Brasil extremamente mutante.

\section{A PERSPECTIVA DO BRASIL}

Ainda em A crise brasileira, Hélio Jaguaribe pressupunha que, uma vez que um dos maiores problemas de sua época consistia no esgotamento das crenças que presidiram nossa formação, a solução para a crise nacional comportava dois aspectos distintos: "de um lado, o repertório de providências suscetíveis de corrigir as mais graves deficiências de que se ressente o país [...] e, de outro lado, a ideologia de que esse programa [fosse] um corolário a cujos princípios estava vinculado [...]"13 (Jaguaribe, 1953b, p. 138). No que tange ao primeiro aspecto, esse diagnóstico foi mais ou menos perene ao longo dos textos publicados nos Cadernos, independentemente de seu autor:

[No plano econômico:] a) regulamentação das aplicações da renda nacional, destinada a ensejar a máxima capacidade de investimento [...]; b) rigoroso controle de intercâmbio internacional, visando a aumentar as exportações, reduzir as importações e selecionar a utilização de divisas; c) reaparelhamento geral, segundo escalas de prioridade por atividade econômica e por regiões; d) racionalização e tecnificação da produção. [No plano social:] a) liquidação dos privilégios hereditários e das forma-

${ }^{13}$ Foi justamente essa dimensão ideológica do pensamento do IBESP, mantido pelo ISEB, que atraiu inúmeras críticas às duas instituições. Ainda nos anos 60, Michel Debrun, Gerard Lebrun e Carlos Guilherme Mota acusaram o ISEB, mais precisamente Álvaro Vieira Pinto, de confundir ciência e ideologia. Foi, porém, em 1978, quando da publicação de ISEB: Fábricas de ideologias por Caio Navarro de Toledo, livro referendado por Maria Silvia de Carvalho Franco, em Ideologia e mobilização popular, que se verifica a percepção de que o ISEB, longe de tratar de um esforço de pensar o Brasil, consistiu em um esforço para "forjar uma precisa e determinada ideologia”, a ideologia do desenvolvimento econômico sob os moldes capitalistas, que se consagrou. Criticando o ISEB por assumir que "não haveria desenvolvimento sem a prévia formulação de uma ideologia do desenvolvimento nacional”, por apresentá-la como expressão dos interesses gerais da nação e por lhe conferir atributos de cientificidade, acabou por acusá-lo de mistificar e obscurecer as lutas de classes (Toledo, 1982). Bolívar Lamounier, também em 1978, Renato Ortiz em 1985 e Pécaut em 1990, saíram em defesa do ISEB, entendendo que, "não obstante suas imprecisões teóricas", ele foi responsável por um diagnóstico crítico da realidade brasileira, não representando, pois, o pensamento da classe hegemônica (Motta, 2000). 
ções fechadas de classe; b) promoção da circulação de elites, visando a criar quadros dirigentes dotados de efetiva representatividade e exemplaridade; c) formação de um movimento social apoiado numa ideologia e assentado por uma programática, apto a suscitar confiança no futuro e anseio pela realização dos objetivos prefixados. [No plano cultural:] a) criação da cultura brasileira, com a incorporação do patrimônio espiritual do ocidente e a formação de uma compreensão viva da realidade nacional; b) desenvolvimento de uma ação tendente a retirar o máximo de rendimento da crise como fator estimulante da cultura [...]; c) reforma da educação, tornando-a compulsória e geral, orientada para a compreensão e o domínio de nossas circunstâncias e apta a exercer uma ampla seleção de valores; d) imediata criação de um amplo quadro de técnicos e de administradores. [No plano político:] a) liquidação do Estado Cartorial e do parasitismo burocrático e instituição do Estado-serviço e da administração produtiva e eficaz; b) instauração de uma política interna calcada num planejamento geral da ação do Estado em todos os planos da vida nacional; c) instauração de uma política externa calcada na objetiva compreensão dos interesses do Brasil na órbita internacional; d) urgente atendimento dos mais imperativos interesses do país sujeitos à pressão direta ou indireta de outros Estados. (Jaguaribe, 1953b, p. 138-141).

A mesma constância não se verificou, porém, no que dizia respeito à ideologia capaz de "atender às solicitações específicas para integrar, num sistema de crenças e ideias, a programática exigida pelos referidos problemas." (Jaguaribe, 1953b, p. 142). Enquanto, no texto de 1953, se entendia que a ideologia, "apta a integrar, num sistema conjunto, suscetível de eficácia histórica, as soluções requeridas pela problemática nacional”, passava pela desprivatização dos meios de produção ${ }^{14}$ - receita forte-

${ }^{14}$ Em A crise brasileira, Hélio Jaguaribe pressupunha que cada um dos planos sociais tendia a lucrar com essa política, na seguinte medida: 1) plano econômico: tornava planejamento mais viável, possibilitando a aplicação da renda nacional segundo critérios do interesse público, maior controle do câmbio internacional, reaparelhamento geral mais rápido e eficiente, maior racionalização e tecnificação da produção; 2) plano social: permitia uma intervenção gestional com vistas à estabilização dos custos, ao controle dos lucros, ao estabelecimento de uma dependência real entre produção e remuneração, e à liquidação dos privilégios de classe; 3) plano cultural: contribuía para a formação de uma cultura nacional, facilitava a radicação social da cultura na realidade e possibilitava a reforma educacional, a criação e o aproveitamento de um quadro técnico e administrativo; 4) plano político: permitia a supressão do estado cartorial e a formação de um estado de mente influenciada pelo contexto internacional de Guerra Fria, expressão da busca por uma política de terceira posição ${ }^{15}-$, nos anos seguintes, os rumos dos acontecimentos levaram seus autores-editores a pensar a situação brasileira não mais em relação ao quadro global, mas em função de seus dilemas internos (Jaguaribe, 1953b, p. 149). Prova disso é que, no ensaio que encerra os Cadernos, observa-se uma moderação do discurso, quando a questão da socialização dos meios de produção nem ao menos é mencionada. O foco passou, pois, da simples adoção de uma postura de terceira posição face ao conflito mundial, à elaboração e adoção de uma ideologia nacional-desenvolvimentista.

Já no segundo número dos Cadernos, no artigo sobre a Situação política brasileira, (texto de autoria desconhecida), apontou-se, como sua nota mais característica, o enfraquecimento do poder civil. Conforme seu autor ou seus autores, o Brasil vivenciava uma forte crise política, resultado da crescente inadequação das suas instituições à realidade nacional. Não se tratava, apenas, de uma crise do governo (como a oposição queria levar a crer), mas de uma crise das instituições oficiais e representativas da sociedade civil, que "carecem de sua presumida representatividade.” (CNT, 1954b, p. 104).

Segundo o autor (ou os autores), no âmbito da governança, tal crise se assemelharia à crise de 1945, quando o governo tentou transferir, sem sucesso, sua base social para as classes trabalhadoras. Uma vez que elas ainda não tinham condições de arcar com tal respon-

serviço, bem como o planejamento da política interna e externa pelo Estado (Jaguaribe, 1953b, p. 149-160).

${ }_{15}$ Tal busca se fez sentir em diversos artigos, quer de crítica à dependência da América Latina para com os Estados Unidos (A ideologia do governo republicano e a política internacional dos Estados Unidos), quer de incentivo à criação de uma Comunidade de Defesa Latino-americana, com destacado papel do Brasil (A denúncia de João Neves, Golpe de Estado na Argentina), ou mesmo na defesa do comércio com o Leste (Problemas do comércio com o Leste), o que possibilitaria o uso de nossa capacidade produtiva ociosa. Todavia, o que chama mais atenção é o fato de seus autores-editores entenderem que nem o capitalismo nem o socialismo eram necessários, ou suficientes para a resolução dos problemas nacionais. Em A crise brasileira, Jaguaribe chegou a afirmar que "comunismo e capitalismo constituem modelos antitéticos apenas quando considerados artificialmente, em condição estática." (Hollanda, 2012, p. 621). 
sabilidade - o proletariado nacional ainda era historicamente insuficiente, com formação recente, inculto e desprovido de articulação -, isso acabou por significar a perda de suas bases. De modo semelhante, a política trabalhista então praticada pelo segundo governo Vargas assinalou mesmo a perda de sua substância: "hostilizado pela classe mercantil, [o governo] não soube conservar o apoio da burguesia industrial e da classe média e não logrou [...] encontrar bases suficientes no proletariado"16 (CNT, 1954b, p. 110).

Somava-se a isso a crise da própria oposição, que "não se mostra capaz de traçar rumos próprios, em substituição aos que critica" (CNT, 1954b, p. 111). A heterogeneidade econômica e social do país seria responsável tanto pela fragmentação interna dos partidos (que, de fato, continuavam regionais), como pela sua falta de sentido ideológico e programático. Daí que: "ideológica e programaticamente, todos os nossos partidos são iguais, se confundem na mesma falta de ideias e orientação" (CNT, 1954b, p. 114). Sobrepõe-se a isso a organização clientelística dos partidos, que "impede todas as formulações analíticas econômica e socialmente fundamentadas". Eis que se instituiu um divórcio entre a dinâmica político-eleitoral e a econômico-social: as for๖ี ças ligadas ao meio rural "logram prevalecer $\therefore$ na política partidária, imprimindo suas características e interesses", quando já eram as classes urbanas as responsáveis pelo desenvolvimento do país (CNT, 1954b, p. 118).

Conforme o autor (ou os autores), essas duas crises, do governo e dos partidos, reve$\stackrel{2}{\wedge}$ lavam as duas faces da crise vivenciada pelo a poder civil. Elas eram a expressão do "agravaiे mento da inautenticidade de nossas instituições políticas [...], quando apreciadas em fun${ }^{16}$ É importante destacar que esse tom negativo com que aqui se analisou o governo Vargas foi abandonado já no - terceiro número dos Cadernos - provavelmente porque foi I escrito posteriormente a seu suicídio. Aí, ainda que com

certas reservas, seus autores-editores passaram a elogiar

$\circ$ o governo, entendendo seu esforço de transferência das

bases da classe média para o proletariado, como resultado

da impossibilidade de continuar apoiado em uma classe

ษ economicamente marginal (CNT, 1955a). ção da dinâmica do processo econômico-social", e tendiam a ser superadas apenas através da formação "de uma frente comum, econômica, social e política, que mobilize as forças e os interesses mais aptos a promover o desenvolvimento nacional", de modo a impor a prevalência "desses interesses e dessas forças sobre as forças e interesses comprometidos com o status quo e o subdesenvolvimento" (CNT, 1954b, p. 117,119, grifos no original). Uma vez que, naquele contexto, nenhum partido "representa ou pode representar essa forças", defendia-se formação de um movimento novo que, “[...] apoiado nessas forças e liderado por seus mais significativos representantes [...]", pudesse levar a cabo o que era considerado um "grande esforço de salvação nacional” (CNT, 1954b, p. 120).

Seguindo essa tônica - "agravamento da inautenticidade de nossas instituições políticas [...], quando apreciadas em função da dinâmica do processo econômico-social" (CNT, 1954b, p. 117) -, os autores-editores dos Cadernos analisaram os fatos e movimentos políticos característicos do período (moralismo, golpe de agosto e sucessão presidencial), repensando e aprofundando o debate sobre a crise brasileira pari passu com as transformações experimentadas em âmbito mundial. Enquanto essas últimas se traduziram em uma mudança no tom dos artigos - passaram da compreensão e caracterização do quadro de Guerra Fria à análise e crítica da política norte-americana e à defesa de um nacionalismo (não só no Brasil, mas na América Latina como todo), em oposição às ameaças imperialistas -, foi na análise dos primeiros que residiu o maior esforço e a novidade dos Cadernos.

Já no primeiro número da revista, ao procurar responder Por que venceu Jânio Quadros?, Hélio Jaguaribe apontou para certa "moralização da vida pública” brasileira. O autor percebia tal vitória como uma antecipação da nova posição do eleitorado brasileiro, mais precisamente do eleitorado paulista, que, frustrado com o atual estado de coisas e "maduro para compreender a inanidade da politica 
de clientela", sem, porém, encontrar "líderes capazes de formular um novo rumo para suas aspirações públicas”, sem encontrar um movimento para orientá-lo à ação, foi levado a votar em Jânio Quadros como um mecanismo de crítica, de negação da ordem vigente (Jaguaribe, 1953a, p. 100). Todavia, como fica claro em $O$ moralismo e a alienação da classe média (texto de autoria desconhecida e publicado no segundo número da revista), tal opção ou movimento expressava a alienação idealista da classe média e da classe pequeno-burguesa que, por dependerem do status e acreditarem que as coisas eram boas ou más como produto de uma vontade honesta ou não, não eram capazes de aprofundar as causas e condições da inautenticidade do governo. Não percebiam, pois, que "a única solução durável para permanecer na direção do processo político-social do país [exigia] a modificação da estrutura econômica do Brasil” (CNT, 1954d, p. 6), jamais a eleição de líderes populistas que, saídos da classe dominante, apelavam, mobilizavam politicamente as massas apenas "para a conquista do poder", nunca para a "formação de [sua] consciência e organização” (CNT, 1954c, p. 144, 146).

Daí que, quando da publicação do terceiro número dos Cadernos, logo após a deposição e o suicídio de Vargas, foram justamente a alienação e o moralismo dessas classes os principais responsabilizados. Em $O$ golpe de agosto e As eleições de outubro, (ambos são textos de autores desconhecidos), o golpe foi caracterizado como algo semelhante ou equivalente ao golpe de 1945: "a classe média, não podendo mais dar uma orientação própria ao processo político-social do país, se torna reacionária” (CNT 1955a, p. 4). Espécie de tática para "deter o curso da história a fim de reconstruir o paraíso perdido do pré-capitalismo”, tal posição expressava a crise da pequena burguesia que, "tendo perdido a possibilidade de dar uma solução própria ao processo político-social do país, aderiu à ideologia e submeteu-se à liderança da burguesia mercantil” - então o setor mais consciente de seus interesses e mais bem organizado para defendê-los (CNT, 1955b, p. 34). Somavam-se a isso os próprios erros do segundo governo Vargas, que, não obstante "a insuficiência dos métodos personalísticos para fazer a política requerida pelas condições históricas", limitou sua política a um maquiavelismo psicológico, quando o que se exigia era uma ação ideológica capaz de modificar as relações entre as classes. Acabou por ficar sem qualquer amparo que não o princípio formal da autoridade, o que permitiu sua deposição (CNT, 1955b, p. 36).

A despeito disso, e ainda nesse mesmo número dos Cadernos, no texto (mais uma vez de autoria desconhecida) O legado político de Vargas e as possibilidades de sua potencialização ideológica, seu autor viu o suicídio de Vargas e sua carta como portadores de um significado político fundamental, pois operaram "uma iluminação emocional na consciência do proletariado, fazendo-o compreender que os móveis da luta nacional eram o interesse de classe e das forças reacionárias e antinacionais" (CNT, 1955c, p. 22). Uma vez que sua carta-suicídio delineava os pontos básicos de uma política de emancipação nacional - desenvolvimento econômico, proteção ao trabalhador e luta contra a espoliação da economia nacional -, bastaria, pois, que a "burguesia industrial e a intelligentsia técnica exerçam o papel a que historicamente estão convocadas", para que seja empreendida uma ação transformadora do Brasil (CNT, 1955c, p. 22).

Isso explica por que o texto $A$ sucessão presidencial (publicado no quarto número dos Cadernos e de autoria de Hélio Jaguaribe), de 1955, polarizou-se em torno de duas bandeiras, a do "juscelinismo", identificado com o "getulismo", e a do "antijuscelinismo" ou "antigetulismo". Conforme o autor tratava-se do embate entre duas posturas econômico-sociais diferentes: desenvolvimento versus colonialismo e (ou) desenvolvimento versus caos. Ou seja, uma volta às linhas mestras do quadro político-social do governo Vargas, com a diferença de que o debate, agora, se transferia para 
o plano "ideológico-programático", pois o programa de desenvolvimento se apoiava mais na atração do empresário brasileiro que na intervenção direta do Estado, e o programa social se fundava mais na elevação do padrão de vida do proletariado do que em um assistencialismo paternalista (Jaguaribe, 1955, p. 6).

Foi, porém, em Para uma política nacional de desenvolvimento (ensaio de encerramento da revista e de autoria desconhecida), que tais análises se traduziram em uma nova proposta para o Brasil. Pressupondo que os problemas do Brasil são bastante simples, posto que "as questões mais importantes e urgentes são as que se referem à produção e à produtividade”, e não à sua distribuição, o autor procura pensar as medidas necessárias para consolidar, finalmente, a passagem do Brasil da fase semicolonial à fase de pleno desenvolvimento. Introduziu-se, aí, a ideia de fases de desenvolvimento (CNT, 1956c, p. 54). Termo cunhado por Guerreiro Ramos, ${ }^{17}$ consistia no reconhecimento de que "as comunidades pertencentes a um mesmo processo histórico global tendem a percorrer as fases determinadas pelo curso desse processo" (Ramos, 1954, p.190). Cada uma dessas fases constituía, por sua vez, uma estrutura-tipo de relações que orientavam toda a vida da comunidade. Nesse sentido, o entendimento da situação do país อิ passava pela compreensão da estrutura-tipo se$\therefore$ gundo a qual se ordenava a sociedade brasileira, acompanhada da compreensão da faseologia de suas origens (CNT, 1956c).

¿ volvimento econômico-social, mas em fase de

ơ acentuado desenvolvimento que, no entanto, $\overrightarrow{>}$

¿ิ 17 Segundo Martins, a concepção de fase de desenvolvimento foi utilizada por Guerreiro Ramos para "rejeitar as

$\stackrel{\pi}{\geq}$ teorias e as soluções praticadas por países avançados", స pois permitia estabelecer as especificidades da situação nacional. Tal ideia, fortemente marcada pelo existencia-

Iismo, definia fases na história brasileira (agrária, de tran-

sição), nas quais predominariam determinadas leis gerais

(lei da complementariedade, lei da autodeterminação) o

que, por sua vez, caracterizaria uma estrutura econômi-

co-social específica, à maneira mannheimiana (Martins, 2008, p. 99). se encontrava obstado por determinados pontos de estrangulamento. Exemplo disso era o fato de o país se encontrar em plena fase de industrialização, aumentando constantemente sua produção, mas ainda dependente de um único produto de exportação: o café. Tal quadro exigia que fossem ponderadas as medidas necessárias para "promover o crescimento de nossa economia sem que ela seja destruída pelos desequilíbrios que tal crescimento ocasiona”: inflação, complexo escassez-caristia, e subdesenvolvimento (CNT, 1956c, p. 89).

De acordo com o autor (ou os autores), longe de limitar o debate a termos monetaristas (caso da disputa entre deflacionistas e inflacionistas $^{18}$ ), "os desequilíbrios estruturais que experimenta nossa economia, em consequência mesmo de seu crescimento, só podiam ser superados com a definitiva transformação da [sua] atual estrutura-tipo", isto é, promovendose o desenvolvimento (CNT, 1956c, p. 90). Para tal, fazia-se necessário reequilibrar a balança comercial brasileira, aumentando suas exportações, ao passo que se substituíam as importações e se expandia sua infraestrutura, de modo a atender à demanda interna por transporte e energia. Uma vez que isso requeria grande volume de capital, item em falta nacional e internacionalmente, "a modificação das condições produtivas exige uma intervenção planificadora do Estado que, direta ou indiretamente, organize a economia do país para os fins em vista, estimule ou desestimule determinadas atividades, coordene fatores, discipline os investimentos e assuma, promocional ou supletivamente, certos encargos produtivos." (CNT, 1956c, p. 94).

Todavia, conforme o autor (ou os autores), só tal intervenção não bastava. Outras duas condições eram necessárias para romper "o impasse do crescimento econômico - desequilíbrios estruturais sem prejuízo do desenvolvimento econômico" (CNT, 1956c, p. 94). De um lado, a mobilização de recursos específicos em

${ }^{18}$ Aí há uma referência ao debate gestado entre Eugenio Gudin e intelectuais desenvolvimentistas da CEPAL (Bielschowsky, 2000). 
moeda estrangeira e nacional. De outro, a existência das condições institucionais necessárias "para que os recursos, aplicados de acordo com os planos, atinjam, efetiva e adequadamente, os resultados programados" (CNT, 1956c, p. 202). Para tanto, a questão do planejamento, do trabalhismo produtivo e nacionalista, bem como da reforma do governo despontavam na análise.

No que tange ao planejamento, utilizando a definição de Laudauer, ${ }^{19}$ pressupunha-se, como setores e relações a serem abrangidos pelo planejamento brasileiro, todos aqueles necessários para assegurar condições ótimas para o desenvolvimento econômico e social. Sugeria-se aí, pela primeira vez, a ideia do desenvolvimento como processo social global, entendendo-se como relações a serem abrangidas pelo planejamento brasileiro todas aquelas necessárias para assegurar condições ótimas para o desenvolvimento econômico e social. Isso significa envolver tanto setores econômicos (comércio exterior, câmbio, atividades de infraestrutura), como setores relativos à educação social, saúde, relações sociais e à organização do Estado. Combinando planos já traçados com elementos novos, advogavam, ao final, a formação de um Plano Nacional de Desenvolvimento.

Já quanto ao segundo aspecto (o trabalhismo produtivo e nacionalista), retomando a discussão acerca do descompasso instituído entre a vida civil e a política nacional, entendiam como saída para a crise a promoção de uma convivência cooperativa das classes, "baseada no comum esforço de promoção do desenvolvimento econômico e subordinada a uma equitativa distribuição dos sacrifícios para tal necessários” (CNT, 1956c, p. 125). Tal possibilidade seria proporcionada pelo Brasil, tendo em vista a característica peculiar de sua luta de classes - havia interesse recíproco pelo desenvolvimento. Sugeriam a "liderança da vida econômica e política pelas forças mais

${ }^{19}$ Planejamento é "a orientação das atividades econômicas por um organismo da comunidade, mediante um projeto que descreva, em termos quantitativos e qualitativos, os processos de produção que devem ser empreendidos durante um período prefixado" (CNT, 1956c, p. 105). diretamente interessada na perseguição desse objetivo" (CNT, 1956c, p. 125). Vale notar que, segundo o autor (ou os autores), isso não implicava a superação das forças representativas do antigo ordenamento, mas o "justo enquadramento de todas as classes” na organização para o desenvolvimento. Ou seja, tratava-se de transformar as velhas oligarquias latifundiário-mercantis "numa classe de modernos agricultores e de eficientes homens de negócio, [superando] o antagonismo que separa os interesses agrícolas e comerciais industriais" (CNT, 1956c, p. 126).

Denominando tal política de trabalhismo produtivo e nacionalista, ${ }^{20}$ apontavam para uma programática social em torno de cinco pontos:

1. Democracia representativa, baseada no sufrágio universal, secreto e igualitário.

2. Igualdade efetiva de oportunidades para todos os cidadãos.

3. Seleção, pela capacidade e produtividade do trabalho, de todos os que devam exercer qualquer função social.

4. Garantia do sindicalismo livre, assegurando-se às entidades de classe plena participação na promoção da fiscalização de seus interesses.

5. Fixação de um padrão mínimo de vida para todos os cidadãos, ajustado ao preço das utilidades. (CNT, 1956c, p. 127)

Por fim, a questão da reforma do governo remetia à crise do estado cartorial. Conforme o autor (ou os autores), a estrutura-tipo de uma comunidade determinava a modalidade de Estado a se construir. Como vimos, até os anos 30 , a sociedade brasileira caracterizavase como semicolonial e subdesenvolvida, com uma economia pautada na monocultura de exportação e com base latifundiária. Seu processo político se realizava em termos da política de clientela e seu modelo de Estado era o estado cartorial. Todavia, quando de seu desen-

${ }^{20}$ Trabalhismo: "é pelo valor e pela produtividade que se deve ajustar a posição de cada cidadão na sociedade"; produtivo: "significa um comum esforço de todos com o objetivo de reservar para fins produtivos a maior cota possível de renda nacional"; e nacional: "organiza o Brasil para o povo brasileiro, rompendo todos os vestígios de semicolonialismo e assegurando plena emancipação econômico-social do nosso país e da nossa gente" (CNT, 1956c, p. 127). 
volvimento econômico, a estrutura social se transformou, mas o cartorialismo não chegou a ser desmontado, quer pelo controle do eleitorado do interior pelas oligarquias rurais, ou pela ausência de consciência de seus interesses por parte das demais classes, quer pelo posicionamento da burguesia mercantil em favor do atual estado de coisas. De uma maneira ou de outra o fato é que a manutenção do cartorialismo para além da sua fase correspondente levou ao agravamento crítico e insuportável da inépcia e da alienação do Estado, chegando mesmo a representar riscos à soberania e aos interesses nacionais. Daí que o momento de impasse "constitui a última oportunidade para sua reforma [do Estado] e seu reajustamento às necessidades do país", ou tal reequilíbrio poderia se impor "mediante uma involução do processo econômicosocial" (CNT, 1956c, p. 145).

Frente a isso, defendiam a atuação imediata "de uma vanguarda esclarecida e eficaz, apta a despertar [...] o esclarecimento ideológico" das novas forças dirigentes de nosso processo econômico-social (CNT, 1956c, p. 146). Reconhecendo-a como portadora de uma ideologia autêntica, porque capaz de promover a máxima "evolução faseológica compatível com a estrutura-tipo [...] e as relações de produção em que se baseia" a sociedade brasileira, advogavam a instituição de um Estado funcional (CNT, 1956c, p. 246). A instituição desse Estado era entendida como "a estruturação e o funcionamento do Estado em condições que o capacitem a realizar eficazmente suas finalidades político-administrativas”. Isso expressava uma mudança não apenas nos fundamentos do $\therefore$ poder, no sentido de recuperar suas bases eco\& nômico-sociais, mas também de seus fins, con今 vertendo-se "no sistema de normas e no apa-

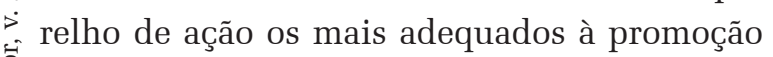
do desenvolvimento e da emancipação econômico-social do país” (CNT, 1956c, p. 245). O Estado assumia, assim, uma postura ativa e dinâmica bastante diferente da passividade característica do estado cartorial.

Apesar de o texto apresentar preocupa- ções de ordem social e política, vale notar que a proposta para o Brasil nele contida tinha a questão econômica, a promoção do desenvolvimento econômico, como questão central, isto é, demandava-se uma reforma do Estado, porque o país precisava de um Estado apto a planejar e executar o desenvolvimento econômico. Advogava uma nova programática social, mas para que as classes participassem e perseguissem livremente seus objetivos, que, necessariamente, passavam pelo desenvolvimento econômico.

Se, como bem pontua Bariani (2005, p. 251), a preocupação central dos autores ibespianos sempre foi "acerca das possibilidades e formas de alcançar o desenvolvimento, [então] pensado como a transformação qualitativa e geral" do Brasil, e não apenas como um empreendimento industrial e comercial, no texto de encerramento dos Cadernos, seu autor (ou os autores) já parecia acreditar que a promoção do desenvolvimento econômico bastava, pois era a saída necessária à superação dos demais planos da crise nacional. O desenvolvimento econômico despontava (como já vinha sendo a tônica, cada vez mais, dos Cadernos) como o problema central do Brasil na perspectiva do seu tempo.

Exemplo disso é que, no texto Significação do nacionalismo (publicado no quarto número da revista) de Hermes Lima, ele reconhecia como desafio do Brasil "completar [sua] maioridade econômica" e passar de um país subdesenvolvido à "condição de país dotado de uma infraestrutura econômica e industrial" (Lima, 1955, p. 87). Nesse sentido, o nacionalismo não deveria ser pensado em termos da "recusa ou desinteresse" pela ajuda técnica e financeira dos países e capitais estrangeiros, mas como um plano de trabalho, uma batalha "contra o atraso técnico e industrial" do país, posto que a transformação de sua estrutura produtiva trazia consigo conquistas sociais de grande monta: possibilitava a incorporação, na estrutura de produção e trabalho, da população até então excluída, pois lhe permitia "viver 
decentemente" (Lima, 1955, p. 87). De modo semelhante, em conferência proferida no clube de engenharia, em 1956 (e publicada no livro Condições institucionais ao desenvolvimento), Hélio Jaguaribe (1958, p. 29) assim resumiu os desafios do Brasil:

[...] se considerarmos mais profundamente as relações entre o Estado [digamos entre a superestrutura social] e a economia, e atentando ao fato de que, dado certo prazo, todo processo econômico tende a criar as instituições necessárias para discipliná-lo, verificaremos a inevitabilidade da superação do Estado Cartorial e a política de clientela. O desenvolvimento brasileiro, gerando uma industrialização crescente, proporcionando à classe média inserção cada vez maior no processo produtivo [...]; proporcionando ao proletariado condições crescentes de renda [...] e às classes rurais condições de elevação da sua renda real mediante a tecnificação da produção, [ou seja] criando as condições que transformam radicalmente o antigo quadro do semicolonialismo do subdesenvolvimento não pode deixar de alterar a estrutura estatal que ainda subsiste. [...] [Logo] na medida em que o país atinge um grau superior de desenvolvimento, impede [-se] que as relações entre o homem público e o seu eleitorado sejam relações de barganha clientelística e suscita outra forma de política.

Logo, para o IBESP e os Cadernos, o desafio do seu tempo era alargar a propaganda do desenvolvimento, mostrando às grandes massas "a dependência que existe entre o processo econômico e a elevação do seu nível de vida”; esse desafio está em claro compasso com seu conteúdo mannheimiano (Jaguaribe, 1958, p. 49).

Ironicamente, enquanto seus autores-editores davam mostras de se contentarem com investigar aquilo que era necessário à realização do desenvolvimento econômico do país (tal como foi prática nos primeiros anos do ISEB), Guerreiro Ramos continuava a insistir em seu projeto de compreender o que havia de bom (inconsciente sociológico) e, tendo em vista o que havia de ruim (a ideologia da jeunssse dorée), elaborar uma sociologia autenticamente brasileira. São essas divergências que levarão à crise e à posterior cisão do ISEB em 1958.

\section{NOTAS FINAIS}

De maneira geral, o estudo dos Cadernos aqui empreendido aponta para dois aspectos distintos, porém complementares: o objetivo central de seus autores-editores foi tanto pensar e entender o Brasil em suas falhas e faltas, como formular um projeto em direção à mudança social, ao desenvolvimento do país. Ambos os objetivos estavam diretamente relacionados à postura intelectual de seus membros e aos desafios postos pelo contexto. Se, a princípio, eles foram levados a analisar e a diagnosticar a crise brasileira em conjunto e, ao mesmo tempo, em resposta ao quadro mundial de Guerra Fria, a partir do terceiro número da revista, tendo em vista que as questões nacionais se tornavam cada dia mais intensas, eles tiveram de (ou mesmo preferiram) diminuir suas preocupações para com o cenário mundial, assim como o conteúdo essencialmente ideológico de suas análises. Foi nesse momento que a busca pelos caminhos do desenvolvimento econômico se sobrepôs, ou, na verdade, resumiu o projeto inicial de promoção de uma mudança social de caráter mais geral.

A meu ver, ao acreditarem que, no Brasil, subsistia certa correspondência entre os interesses situacionais de classe e que o desenvolvimento econômico, por si só, possibilitaria a superação dos quatros planos da crise nacional, para aos intelectuais do IBESP, passou a bastar estudar as formas de alcançá-lo, o que se tornou chave para a realização da mudança social por eles demandada. Por um lado (e em sentido contrário à crítica de Toledo), isso esteve diretamente relacionado ao contexto específico a partir do qual seus autores escreviam. Vale lembrar que, nos anos 50, a agenda temática girou quase que exclusivamente em torno dos "questionamentos sobre o atraso e sobre as possibilidades de desenvolvimento da sociedade brasileira", a ponto de o próprio PCB empunhar a bandeira do nacional- desenvolvimentismo, ainda que visando a outros propósitos - a consolidação do capitalismo na- 
cional como etapa fundamental para a revolução socialista (Martins, 2008, p. 76). Por outro, expressava o projeto maior do grupo que, para além de interpretar de forma neutra os dilemas e desafios da realidade brasileira, procurava converter seu saber em influência, para pensar e agir não só para a sociedade, mas pela sociedade (historicamente incapaz).

Na medida em que percebiam que as classes nacionais eram inconscientes de seus interesses - ainda eram bastante débeis, imediatistas e sensíveis apenas às altas e baixas dos salários (CNT, 1955c, p. 53) - e que "os móveis da luta nacional eram o interesse de classe das forças reacionárias e antinacionais”, os intelectuais do IBESP demandavam às vanguardas (que eles mesmos integravam) uma ação não no sentido de desvelar as principais questões, os principais dilemas do país, mas uma ação no sentido de educar e organizar ideologicamente as massas, de modo a assegurar o apoio popular necessário para que as policies em favor do desenvolvimento encontrassem " o suporte das grandes massas" e pudessem "ser convertidas em ação administrativa corrente” (CNT, 1955c, p. 22). Eles parecem atribuir a si mesmos um papel muito mais importante do que até mesmo Mannheim havia pretendido para sua intelligentsia. Por terem "uma verdadeira ๑ visão de conjunto", não só se colocavam além das ideologias, tinham, antes, o poder de cons$\stackrel{8}{4}$ truir a verdadeira ideologia. Acreditavam, pois, "situar-se além e adiante" da situação nacional, so antecipando a alternativa necessária, mas ainda não percebida pela sociedade, mesmo sem haver consenso sobre qual seria essa alternativa (Schwartzman, 1979, p. 4).

Recebido para publicação em 02 de outubro de 2014 Aceito em 20 de julho de 2015

\section{REFERÊNCIAS}

BARIANI, Edison. Uma intelligentsia nacional: grupo de Itatiaia, IBESP e os cadernos de nosso tempo. Caderno CRH, Salvador, Ba, n. 44, p. 249-256, 2005.
BIELSCHOWSKY, Ricardo. Pensamento econômico brasileiro: o ciclo ideológico do desenvolvimentismo. Rio de Janeiro: Contraponto, 2002.

BITTENCOURT, André. O Brasil e suas diferenças. 2001. 203p. Dissertação (Mestrado em Sociologia) - Programa de Pós-graduação em Sociologia da Universidade Federal do Rio de Janeiro, Rio de Janeiro, 2001.

CNT. Apresentação. Cadernos do Nosso Tempo. Rio de Janeiro, IBESP, n. 1, p. 1-2, 1953a.

. A denúncia João Neves. Cadernos do Nosso Tempo, Rio de Janeiro, IBESP, n. 2, p. 83-100, 1954a.

Situação política brasileira. Cadernos do Nosso $\overline{T e m p}$, Rio de Janeiro, IBESP, n.2, p. 102-122, 1954b.

Que é ademarismo?. Cadernos do Nosso Tempo, Rio de Janeiro, IBESP, n. 2, p. 129-149, 1954c.

O moralismo e a alienação da classe média. Cadernos do Nosso Tempo, Rio de Janeiro, IBESP, n. 2, p.150-159, 1954d.

O Golpe de agosto. Cadernos do Nosso Tempo, Rio de Janeiro, IBESP, n. 3, p. 01-22, 1955 a.

As eleições de outubro. Cadernos do Nosso Tempo, Rio de Janeiro, IBESP, n. 3, p. 23-29, 1955b.

O legado político de Vargas e as possibilidades de sua potencialização ideológica. Cadernos do Nosso Tempo, Rio de Janeiro, IBESP, n.3, p. 31-48, 1955c.

Sentido e perspectivas do Governo Kubitschek. Cadernos do Nosso Tempo, Rio de Janeiro, IBESP, n.5, p. 1-18, 1956a.

Golpe de estado na Argentina. Cadernos do Nosso $\overline{T e m p}$, Rio de Janeiro, IBESP, n. 5, p. 33-46, $1956 \mathrm{~b}$.

Para uma política nacional de desenvolvimento. Cadernos do Nosso Tempo, Rio de Janeiro, IBESP, n.4, p.4788, 1956c.

FERNANDES, Oscar Lorenzo. Análise existencial da realidade brasileira. Cadernos do Nosso Tempo, Rio de Janeiro, IBESP, n. 4, p.118-136, 1955.

HOLLANDA, Cristina Buarque. Os Cadernos do Nosso Tempo e o interesse nacional. Dados, Rio de Janeiro, n. 3, p. 607-640, 2012.

JAGUARIBE, Hélio. Porque venceu Jânio Quadros? Cadernos do Nosso Tempo, Rio de Janeiro, IBESP, n.1, p. 99-102, 1953a.

A crise brasileira. Cadernos do Nosso Tempo, Rio de Janeiro, IBESP, n.1, p. 120-160, 1953b. . . A Crise do nosso tempo e do Brasil. Cadernos do Nosso Tempo, Rio de Janeiro, IBESP, n. 2, p. 1-17, 1954.

. A sucessão presidencial. Cadernos do Nosso Tempo, Rio de Janeiro, IBESP, n. 4, p. 1-23, 1955.

Jaguaribe, Hélio. O nacionalismo na atualidade brasileira. Rio de Janeiro, ISEB, 1958.

. O ISEB e o desenvolvimento nacional In: TOLEDO, Caio Navarro. Intelectuais e política no Brasil. A experiência do ISEB. Rio de Janeiro: Revan, 2005. p.14-55.

LIMA, Hermes. Significado do nacionalismo. Cadernos do Nosso Tempo, Rio de Janeiro, IBESP, n. 4, p. 85-100, 1955. MANNHEIM, Karl. Sociologia da Cultura. São Paulo: Perspectiva, 1974.

MARTINS, Tatiana Gomes. Florestan Fernandes e Guerreiro Ramos: para além de um debate. 2008, 223 p. Tese (Doutorado em Sociologia) - Programa de PósGraduação em Sociologia da Universidade Estadual de Campinas, São Paulo, 2008.

MOTTA, Luiz Eduardo. O ISEB no banco dos réus. Comum, Rio de Janeiro, n. 15, p. 119-145, 2000. 
RAMOS, Guerreiro. O problema do negro na sociologia brasileira. Cadernos do Nosso Tempo, Rio de Janeiro, IBESP, n. 2, p. 189-220, 1954.

. A ideologia da Jeunesse Dorée. Cadernos do Nosso $\overline{T e m p}$, Rio de Janeiro, IBESP, n. 4, p. 101-112, 1955.

O inconsciente sociológico. Cadernos do Nosso

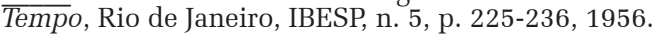

PÉCAUT, Daniel. Os intelectuais e a política no Brasil. São Paulo: Ática, 1990.

PEREIRA, Alexsandro Eugênio. O ISEB na perspectiva do seu tempo. 2002. 325 p. Tese (Doutorado em Ciência política) - Programa de Pós-Graduação em Ciência Política da Universidade estadual de São Paulo, São Paulo, 2002.
Intelectuais, política e cultura na formação do ISEB. In: TOLEDO, Caio Navarro. Intelectuais e política no Brasil. A experiência do ISEB. Rio de Janeiro: Revan, 2005. p. 253-260.

SCHWARTZMAN, Simon. Pensamento nacionalista e os Cadernos de Nosso Tempo. Brasília: Editora da Universidade de Brasília, 1979.

SODRÉ, Nelson Werneck. A verdade sobre o ISEB. Rio de Janeiro: Avenir, 1978.

TOLEDO, Caio Navarro. ISEB: Fábrica de Ideologias. São Paulo: Ática, 1982.

(Org.). Intelectuais e política no Brasil. A experiência do ISEB. Rio de Janeiro: Revan, 2005 
THE IBESP AT HIS TIME: a genetic and chronological analysis of Cadernos do Nosso Tempo

\section{LE IBESP A SON EPOQUE: une analyse génétique et chronologique des Cadernos do Nosso Tempo}

\section{Fernanda Xavier da Silva}

This paper presents an analysis of the Cadernos do Nosso Tempo magazine. Published between 1953 and 1956 by IBESP (Brazilian Institute of Economics, Sociology and Politics), marked an effort of national intelligence in promoting genuinely Brazilian thought. Combining articles of sociological, political, economic and cultural interpretation of Brazil, with the analysis of the phenomena of that time, consolidate a broad diagnosis of the country, a stinging analysis of the conditions and ways to achieve development. Main mobile, theme that united all IBESP intellectuals, was present in all numbers of Cadernos without remain unchanged. In our view, since the ideas seek to respond to the challenges and dilemmas placed by the particular context, the way that the development has been thought changed jointly to the transformations experienced in the country; that makes important to study Cadernos genetic and chronologically.

Keywords:Braziliansocialthought.Developmentalism. IBESP. Cadernos do Nosso Tempo.
Cet article présente une analyse de la magazine Cadernos no Nosso Tempo. Publié entre les années 1953 et 1956 par IBESP (Institut brésilien de économie, sociologie et politique), a marqué un effort de l'intelligence nationale pour stimuler une pensée véritablement brésilienne. Combinant articles de interprétation sociologique, politique, économique et culturel du Brésil, avec l'analyse des phénomènes de son époque, a consolidé un large diagnostic du pays, une analyse cinglante des las conditions et des moyens de parvenir le développement, thème principal, mobile, qui a uni les intellectuels de IBESP, était présent dans tous les numéros de Cadernos sans rester immutable. À notre avis, comme les idées visent à répondre aux défis et aux dilemmes posés par le contexte particulier, l'idée de développement a changé ensamble les transformations connus par le pays; comme çá, il est important d'étudier les Cadernos génétique y chronologiquement.

Mots-CLÉs: Pensée sociale brésilienne. Développementalisme. IBESP. Cadernos do Nosso Tempo. Brasileiro, trabalhando especificamente com pensamento autoritário, IBESP e ISEB. Publicações recentes: As quatro faces de Oliveira Vianna. Política \& Sociedade (Online), v. 14, p. 132, 2015; As constituições da era Vargas: uma abordagem à luz do pensamento autoritário dos anos 30. Política \& Sociedade (Impresso), p. 259-288, 2010. 